\title{
Lactobacilli infection case reports in the last three years and safety implications
}

\author{
Franca Rossi ${ }^{1, *}$, Carmela Amadoro ${ }^{2}$ and Giampaolo Colavita ${ }^{2}$
}

1 Diagnostica Specialistica, Sezione di Campobasso, Istituto Zooprofilattico Sperimentale dell' Abruzzo e del Molise “G. Caporale”, via Garibaldi 155, 86100, Campobasso, Italy; f.rossi@izs.it

2 Medicine and Health Science Department "V. Tiberio", University of Molise, Via de Santis, 86100 Campobasso, Italy; carmela.amadoro@unimol.it; colavita@unimol.it

* Correspondence: $\underline{\text { f.rossi@izs.it }}$

\begin{abstract}
Lactobacilli constitute the dominant microbiota in many fermented foods and comprise widely used probiotics. However, these bacteria caused rare infections mostly in diabetic and immunocompromised subjects in presence of risk factors such as prosthetic hearth valves and dental procedures or caries.

The scope of this survey was re-assessing the pathogenic potential of lactobacilli based on the infection case reports published in the last three years. In 2019, 2020 and 2021 17, 15 and 16 cases, respectively,.including endocarditis, bacteremia and other infections, were reported. These annual numbers are higher than observed previously. Lacticaseibacillus rhamnosus (13 cases), comprising strain GG (ATCC 53103) with established applications in healthcare, L. paracasei (7 cases), Lactobacillus acidophilus (5 cases), L. jensenii (5 cases), Lactiplantibacillus plantarum (3 cases), L. paraplantarum, L. delbrueckii subsp. delbrueckii, L. gasseri, L. paragasseri, Limosilactobacillus fermentum and L. reuteri (1 case each) were involved.

Virulence characterization of two strains that caused infections, a derivative of L. rhamnosus GG and L.paracasei LP10266, indicated that increased biofilm forming capacity favors pathogenicity and it is determined by variable genetic traits.

This survey highlighted that strains of lactobacilli able to cause infections were little characterized genetically. Instead, to avoid that these bacteria become a hazard, genetic stability should be periodically re-evaluated by whole genome sequencing (WGS) to ensure that only non-pathogenic variants are administered to vulnerable individuals.
\end{abstract}

Keywords: lactobacilli infections; update; case reports; virulence traits; safety implications

\section{Introduction}

Lactobacilli, i.e. bacteria belonging to species included in the genus "Lactobacillus" before it was divided in 25 new genera in 2020 [1], are Gram-positive anaerobic aerotolerant asporigenous bacteria with a rod cell shape. These are responsible for fermentative processes in foods where they convert carbohydrates to organic acids, ethanol and $\mathrm{CO}_{2}$, with lactic acid as the sole or one of the main metabolic products. These bacteria are intimately connected with human wellbeing, since they are able to colonize different body sites such as the oropharynx, gastrointestinal tract (GIT), and female urogenital tract where they contrast pathogenic microorganisms. Lactobacilli are ingested through the consumption of traditional fermented products. Representatives of these food products are manufactured in all parts of the world, where they have been a component of human diet throughout millennia. In fermented foods lactobacilli release organic acids and other substances with antimicrobial properties that allow to obtain microbiologically safe, nutrient rich fermented matrices of animal and plant origin. Lactobacilli enhance the nutritional value of these foods by increasing their digestibility, and act as living component that help to prevent and treat many health disorders. In some countries, fermented foods were usually prepared according to traditional methods without addition of well characterized bacterial cultures. These foods are perceived as safe by consumers and are commonly considered to contain living microorganisms with health promoting effects [2].

Foods can benefit of the definition "probiotic" when they contain bacterial strains that exert beneficial effects on the host when administered in adequate amounts [3] and their beneficial effects were proven by clinical studies. This is also true for fermented 
foods. These can be defined "probiotic" if their beneficial effects were proven and depend on the presence of microbial strains with a probiotic action [4]. Single strains of lactobacilli have well recognized effectiveness in the prevention and treatment of diseases of infectious or other nature and hold the generally recognized as safe (GRAS) status conferred by the Food and Drug Administration (FDA) in the USA [5]. In Europe, all species belonging to the old genus Lactobacillus reclassified in 2020 and intended for use in food products hold the qualified presumption of safety (QPS) status recognized by the European Food Safety Authority [6]. The market of probiotic lactobacilli has been growing constantly and has perspectives of further increases in the years to come [7], since these bacteria are used for the production of probiotic foods, food supplements and pharmaceutical preparations designated as "live biotherapeutic products" (LBPs) that are intended for treatment of specific medical conditions. The latter may include one or more bacterial strains, must be stable in composition and efficacy and must be safe on the basis of standardized evaluation protocols [8].

The assumption of probiotics is well accepted by consumers who are increasingly aware of their beneficial effects. On the other hand, current regulations still do not ensure that all the probiotics commercially available have a proven efficacy [9].

On the other hand, lactobacilli have also the potential to cause infections, that are considered to be rare on the basis of the number of case reports published until 2019. Infections caused by lactobacilli, have been mostly reported in immunocompromised and diabetic patients, but sometimes also in subjects without underlying conditions or risk factors [10].

This new survey of case reports, limited to the last three years, was carried out to collect updated knowledge on the involvement of lactobacilli in infections. The aim was to obtain indications on the current trend and on how to reduce the risk that these bacteria cause disease when ingested with fermented food, probiotic food, food supplements and LBPs. This aspect deserves attention especially because reported episodes of infections occurred primarily in patients with medical conditions, such as preterm birth, diabetes and immunodeficiency in which probiotic lactobacilli constitute a valuable aid $[11,12,13]$.

\section{Cases of lactobacilli infections reported in years 2019, 2020 and 2021.}

In the period 2019 - 2021, 48 case reports of infections caused by lactobacilli, with an almost uniform annual distribution, were published. These were retrieved from scientific literature databases by using the search terms "Lactobacillus", or any of the names of the genera newly classified in 2020 and comprising probiotics [1], followed by the terms "infection" or "bacteremia", or "endocarditis", or "abscess". It must be underlined that none of the case reports or retrospective studies retrieved used the new nomenclature for lactobacilli. Among the case reports found, endocarditis and bacteremia predominated, according to previous records [10]. Table 1 shows the number of cases of endocarditis and bacteremia reported per year, together with the range of patients' age, risk factors, underlying medical conditions and identity of the etiological agents. The references are numbered according to the chronological order of appearance in journals or conference proceedings. Case reports published online in 2021 but appearing on journals in early 2022 are included as 2021 entries, as also in Table S1.

Table 1. Number of case reports per type of infection caused by lactobacilli each year since 2019, with age range of patients, underlying conditions and species identity of the etiological agents. The number of cases per risk factors and underlying condition are reported separately, though in some instances different risk factors and underlying conditions co-occurred in the same patient.

\begin{tabular}{llll}
\hline Year & 2019 & 2020 & 2021 \\
\hline
\end{tabular}




\begin{tabular}{|c|c|c|c|}
\hline n. cases & $6[14,15,16,17,18,19]$ & $10[25,26,27,28,29,30,31,32,33,34]$ & $7[36,37,38,39,40,41]$ \\
\hline range of patients age & $39-75$ & $40-83$ & $48-83$ \\
\hline causative agents & $\begin{array}{l}\text { Lacticaseibacillus paracasei, } \\
\text { unidentified lactobacilli }\end{array}$ & $\begin{array}{l}\text { Lactobacillus acidophilus, L. } \\
\text { jensenii, L. paracasei, L. } \\
\text { rhamnosus, unidentified } \\
\text { lactobacilli }\end{array}$ & $\begin{array}{l}\text { L. jensenii, L. paracasei, L. } \\
\text { rhamnosus }\end{array}$ \\
\hline Risk factors & $\begin{array}{l}6 \text { cases: prosthetic aortic valve } \\
1 \text { case: dental extraction } \\
1 \text { case: septic shock due to acute } \\
\text { cholecistitis } \\
1 \text { case: intravenous drug abuse }\end{array}$ & $\begin{array}{l}3 \text { cases: dental problems (tooth } \\
\text { extraction, teeth scaling, caries) } \\
4 \text { cases: diabetes mellitus } \\
1 \text { case: suspected undiagnosed } \\
\text { structural heart disease }\end{array}$ & $\begin{array}{l}3 \text { cases: none } \\
1 \text { case: aortic stent placement } \\
1 \text { case: transcatether aortic valve } \\
\text { implantation } \\
1 \text { case: mitral valve repair }\end{array}$ \\
\hline Underlying conditions & $\begin{array}{l}2 \text { cases: Birt- Hogg- Dube } \\
\text { syndrome } \\
3 \text { cases: none }\end{array}$ & $\begin{array}{l}1 \text { case: pancytopenia, cirrhosis, } \\
\text { Crohn's disease } \\
1 \text { case: Erdheim-Chester disease } \\
\text { on chemotherapy } \\
1 \text { case: gastroesophageal reflux }\end{array}$ & $\begin{array}{l}1 \text { case: cardiac disease } \\
1 \text { case: hypertension, obstructive } \\
\text { sleep apnoea }\end{array}$ \\
\hline Bacteremia $^{1}$ & & & \\
\hline n. cases & $7[20,21,22,23,24]$ & $1[35]$ & $4[42,43,44,45]$ \\
\hline range of patients age & neonate - 62 & 75 & Neonate - 72 \\
\hline causative agents & $\begin{array}{l}\text { L. acidophilus, L. rhamnosus, } \\
\text { Limosilactobacillus reuteri, } \\
\text { unidentified lactobacilli }\end{array}$ & L. rhamnosus & $\begin{array}{l}\text { L. rhamnosus, Lactiplantibacillus } \\
\text { plantarum }\end{array}$ \\
\hline Risk factors & $\begin{array}{l}1 \text { case: Urinary tract infection } \\
\text { (UTI), } \\
1 \text { case: treatment with } \\
\text { Nivolumab }\end{array}$ & $\begin{array}{l}\text { dental scaling, } \\
\text { immunosuppression for renal } \\
\text { transplantation }\end{array}$ & $\begin{array}{l}1 \text { case: Pre-term birth, CVC } \\
2 \text { cases: treatment with } \\
\text { probiotics } \\
1 \text { case: consumption of } \\
\text { fermented vegetables } \\
1 \text { case: consumption of home- } \\
\text { made yogurt }\end{array}$ \\
\hline Underlying conditions & $\begin{array}{l}2 \text { cases: diabetes mellitus } \\
1 \text { case: lung cancer }\end{array}$ & diabetes mellitus & $\begin{array}{l}1 \text { case: aortic coarctation } \\
1 \text { case: mild hypertension and } \\
\text { colon adenocarcinoma } \\
1 \text { case: HIV infection, Crohn's } \\
\text { disease }\end{array}$ \\
\hline
\end{tabular}

${ }^{1}$ Bacteremia cases considered here are those designated primarily as such by the authors of the case report. 
In Table 2 the types of infection different from endocarditis and bacteremia attributed to lactobacilli in 2019, 2020 and 2021 are listed. Age of the patient, risk factors, underlying conditions and species identity of the infectious agent are shown. Case reports published online in 2021, but appearing on journals in early 2022, are included as 2021 entries, as also in Table S1.

Table 2. Infections different from endocarditis and bacteremia caused by lactobacilli in years 2019, 2020 and 2021.

\begin{tabular}{|c|c|c|c|c|}
\hline Type of infection & Age, sex & Risk factors & Underlying conditions & Causative agent \\
\hline \multicolumn{5}{|c|}{2019} \\
\hline $\begin{array}{l}\text { Meningo-encephalitis and } \\
\text { bacteremia [46] }\end{array}$ & 63 male & & & L. plantarum \\
\hline Septic shock [47] & 54 male & Consumption of probiotic yogurt & $\begin{array}{l}\text { promyelocytic leukemia in second } \\
\text { complete remission }\end{array}$ & L. rhamnosus GG \\
\hline UTI [48] & 49 male & & & $\begin{array}{l}\text { L. delbrueckii subsp. } \\
\text { delbrueckii }\end{array}$ \\
\hline Perinephric abscess [49] & 52 male & & $\begin{array}{l}\text { diabetes mellitus, obesity, mild } \\
\text { hydronephrosis }\end{array}$ & Unidentified lactobacilli* \\
\hline \multicolumn{5}{|c|}{2020} \\
\hline Interstitial pneumonia [50] & 68 female & $\begin{array}{l}\text { L. paraplantarum probiotic } \\
\text { supplementation }\end{array}$ & pancreatic cancer, diabetes mellitus & No cultures carried out \\
\hline Lung abscess [51] & 14 male & $\begin{array}{l}\text { Possible aspiration of lactobacilli } \\
\text { from yogurt }\end{array}$ & $\begin{array}{l}\text { cerebral palsy, epilepsy and asthma } \\
\text { treated with corticosteroids }\end{array}$ & L. rhamnosus \\
\hline $\begin{array}{l}\text { Renal and perinephric } \\
\text { abscesses [52] }\end{array}$ & 26 female & $\begin{array}{l}\text { Interventions to treat } \\
\text { nephrolithiasis }\end{array}$ & & L. jensenii \\
\hline Prosthetic joint infection [53] & 82 female & 2021 & $\begin{array}{l}\text { Past nephrectomy, asthma, } \\
\text { hypertension, dyslipidemia, } \\
\text { hypothyroidism }\end{array}$ & L. paracasei \\
\hline Masticator abscess [54] & 23 female & Wisdom tooth extraction & diabetes mellitus & Unidentified lactobacilli \\
\hline Prostatic abscess [55] & 57 male & & diabetes mellitus, hypertension & L. jensenii \\
\hline Liver abscesses [56] & 59 male & $\begin{array}{l}\text { Multiple abdominal surgeries with } \\
\text { modified biodigestive anatomy }\end{array}$ & diabetes mellitus & L. gasseri \\
\hline $\begin{array}{l}\text { Pancreatic necrosis and } \\
\text { retroperitoneal abscess [57] }\end{array}$ & 88 female & & diabetes mellitus, hypertension & L. paracasei \\
\hline Cavernosal abscess [58] & 63 male & & diabetes mellitus & L. paragasseri \\
\hline
\end{tabular}

* bacterial isolates designated as "Lactobacillus spp." but not identified to the species level.

The description of each case is detailed in Table S1, with indication of the method of identification of the causative agent. In four cases regarding patients with severe underlying conditions the outcome was fatal, though the infection had been resolved by antibiotic treatment $[20,22,34,44]$. This accounted for a mortality rate of $8.3 \%$. 
For eighteen reports, the species involved was specified but the method of identification was not declared. For other nine reports, identification to the species level was not carried out and the agent of infection was designated as "Lactobacillus spp.". One study reported just Gram staining as the method of identification [54]. In the case of interstitial pneumonia published in 2020 (Table 2) cultures were not carried out, but it was assumed that the Lactiplantibacillus paraplantarum strain present in the probiotic yogurt consumed by the patient was the cause, since ground-glass nodules (GGNs) formed in the lungs disappeared after discontinuing the assumption of the probiotic and vildagliptin [50].
Lactobacilli were isolated from
blood $[15,16,17,18,20,21,22,23,24,25,26,27,29,30,31,32,33,34,35,36,37,38,40,41,42,43,44,45,46,47,49$, $52,55,56,57]$, diseased valve tissue [28], abscess fluids [48,51,52,54,57,58], cerebrospinal fluid (CSF) [46], marrow [36], arthrocentesis aspiration fluid [53] in anaerobiosis and, in some cases, also in aerobiosis [40,15]. Use of automated microbial detection system, i.e. BACT/ALERT 3D or the BACTEC systems (BioMérieux) with incubation at $35^{\circ} \mathrm{C}$ were mentioned in some reports $[28,37,40]$. The case reports that described the identification procedures mostly referred of standardized instrumental techniques widely adopted in clinical microbiology laboratories. These were matrix-assisted laser desorption/ionization time-of-flight (MALDI-TOF) mass spectrometry (Table S1), that relies on interpretation of spectra by reference to databases, or colorimetric methods, e.g. Vitek 2 automated identification system, with ANC ID card, BioMérieux) [46,43], or both (Table S1). In one instance, the RapID CB Plus system (Thermo Scientific) was used [23]. Sequencing of the 16S rRNA gene was carried out in six instances and whole genome sequencing in two (Table S1). In one case there was discordance in the identification with MALDI TOF mass spectrometry and 16S rRNA gene sequencing between the strictly related species L. gasseri and L. paragasseri [58].

De Freitas et al. [49] stated that their facility was not equipped for identification to the level of species.

Antibiotic treatment of infections was always successful, though in some cases it was intiated empirically and changed later based on antibiotic susceptibility testing. Susceptility to $\beta$-lactams, including amoxicillin, amoxicillin/clavulanic acid, ampicillin, ampicillin-sulbactam, benzylpenicillin, penicillin G, piperacillin/tazobactam and meropenem IV was reported in most cases. These antibiotics were used singly or in association with gentamicin, clindamycin and clarithromycin $[16,17,20,21,22,23,24,25,26,27,31,32,33,34,36,37,38,41,43,44,45,46,48,49,51,53,54,55,56,57,58]$

\section{Aspects of the lactobacilli infections cases.}

\subsection{Bacteremia.}

In two cases bacteremia was associated to localized infections, namely, liver abscess [21] and urinary tract infection (UTI) [23]. In the case reported by Sendil et al. [35] bacteremia evolved to septic shock.

The origin of the infectious agent was investigated by Chiang et al. 2021 [45], who observed one case of bacteremia in a preterm girl and reviewed cases of neonates with $L$. rhamnosus GG bacteremia reported until November 2019. Beyond the new case, other eight reports were found, all occurring in 2004, in infants of less than three months of age. They could state that in at least $55.6 \%$ of the infants the infection originated from contamination of the central venous catether (CVC) and in three cases the tip of the catether grew L. rhamnosus GG. For the case reported by Celis Castaňeda et al. [20], it was specified that the $L$. reuteri probiotic was administered to the baby according to the institutional protocol. Also in this case a CVC was used and mechanical ventilation was applied.

Haziri at al. [42] hypothesized that the origin of the infectious agent was a yogurt made at home by the patient, though isolates from yogurt were not examined.

\subsection{Endocarditis.}


Most of the cases of endocarditis had a deceitful and slow onset, with or without fever, with weight loss, fatigue, dyspnea, cough, chills, sweats, abdominal pain with nausea and vomiting, lumbar pain, syncope, with valvular vegetations becoming detectable after many days or even months from the beginning of symptoms $[14,15,16,17,18,25,27,28,32,34,36,37,38,40]$. In many cases replacement of the aortic valve $[15,16,17,18,25,26,31,33,36,41]$, in one case replacement of the mitral valve [30] and in another case replacement of both aortic and mitral valves [28] was necessary.

One case occurring in a healthy 50 -year-old male who had as possible risk factors use of a probiotic supplement and a gingival laceration 3 months prior to the clinical manifestations of endocarditis, presented both a lesion of the native mitral valve and a perforation of the native aortic valve. The presence of splenic infarction possibly caused by septic emboli was also reported [28]. In the case reported by Campbell et al. [30] consumption of probiotic yogurt was the sole risk factor and native mitral valve was affected. Argotsinger et al. [39] reported native aortic valve infection in absence of risk factors and medical history.

Complications observed in cases of endocarditis comprised:

- $\quad$ multilevel discitis $[18,34]$;

- $\quad$ occlusion of the superior mesenteric artery for a thrombus, requiring urgent surgical laparotomy, associated to emboli in the brain cortex [40];

- $\quad$ splenic infarct, possibly caused by septic emboli [18, 25, 28];

- multiple embolic strokes with acute-to-subacute infarct in the brain parietal lobe and a rapidly progressive glomerulonephritis (RPGN) [29];

- $\quad$ splenic abscess [25];

- glomerulonephritis and thrombotic microangiopathy [19];

- microabscesses in the psoas [34];

- embolic stroke and presumed lumbar vertebral osteomyelitis [39];

- recurrent transient ischemic attacks possibly related to a central embolic source causing left side lower extremity weakness and expressive aphasia [15];

- $\quad$ peroneal mycotic pseudoaneurysm supposed to be caused by seeding of blood-borne bacteria to the vasa vasorum of the artery wall or septic emboli from the infected heart valve [41];

- $\quad$ acute respiratory failure and septic shock [17];

- infarction secondary to septic embolism and ruptured mycotic brain aneurysm suspected to be caused by septic embolism from the aortic valve vegetation with right-sided hemiplegia and aphasia [14];

- $\quad$ ankle arthritis with cutaneous eruption [27].

One case of septicemia following endocarditis attributed to Lactobacillus jensenii was consequent to asymptomatic urolithiasis with bilateral ureter obstruction [31].

3.3 Other infections caused by lactobacilli and complications.

Case reports of localized infection caused by lactobacilli in the last three years are summarized in Table 2. Many presented complications such as the propagation of the infection to other body districts.

A 63 years old patient affected by lung cancer, who developed meningoencephalitis caused by L. plantarum, also manifested atrial fibrillation, left atrium enlargement and trace of mitral regurgitation, though with no evidence of active endocarditis [46].

Ranchal et al. [55] reported of a large abscess of the prostate caused by L. jensenii extending to the seminal vesicles and pelvic muscles and with bladder fistulization. The case was complicated by bacteremia, pulmonary septic emboli and probable right-sided endocarditis.

In a 49 years old patient, UTI caused by L. delbrueckii [48] was complicated by pyelitis with purulent discharge because of resistance of the causative strain to quinolones, that had been initially used to treat the infection. Recovery was obtained by administering cefotaxime and amoxicillin. 
A case of perinephric abscess in a 26 years-old lady due to L. jensenii and Prevotella bivia was complicated by L. jensenii bacteremia [52].

A pyelonephritis case caused by unidentified lactobacilli, described by De Freitas et al. [49], was complicated by a perinephric abscess, never reported before to be caused by lactobacilli, and bacteremia.

Pancreatic necrosis attributed to L. paracasei, as reported by Miwa et al. [57], was associated with retroperitoneal abscess and bacteremia.

A case report not included in previous reviews but worth of being mentioned for its uniqueness and severity was published in 2018 [59] and regards fasciitis caused by L. acidophilus in a 59 year old diabetic woman. The infection caused an abdominopelvic wound with necrotic tissue along the fascial planes. Repeated operative procedures were necessary to eliminate necrotic tissue that continued to form. Authors stated that cultures of the necrotic tissue revealed the presence of L. acidophilus but the identification method was not specified. Antibiotic treatment with doxycycline and ceftazidime allowed wound healing in thirty days.

\section{Investigations on the frequency of lactobacilli infections.}

Three recent studies analyzed retrospectively the occurrence of infections caused by lactobacilli in two hospitals $[60,61]$ and the intensive care unit (ICU) of a children's hospital [62] and found that numerous cases were recorded in four years, one year and five years, respectively. Albarillo et al. [60] reported that a total of 47 patients had growth of L. rhamnosus or L. rhamnosus/casei from different types of specimens, i.e. blood, abdominal fluid, abscess, pleural fluid, bronchial fluid, urine, and sputum. Since 2015, MALDI TOF spectrometry was used for isolate identification and in 12 cases the species L. rhamnosus and paracasei could not be distinguished. The average age of patients was 63 years with almost the same number of males and females. All the cases had polymicrobial infections and nine patients died for the underlying conditions rather than the Lacticaseibacillus infection. The authors concluded that these lactobacilli have a low pathogenic potential.

Yelin et al. [62] analyzed records in a period of five years finding a significantly higher frequency $(1.1 \%, 6$ of 522 patients) of bacteremia caused by lactobacilli in patients who received the probiotic L. rhamnosus GG compared to those who did not (2 out of $21,652)$. Six isolates were obtained from the patients with bacteremia in the group receiving the probiotic and all were identified as L. rhamnosus by MALDI-TOF mass spectrometry, while two isolates from the bacteremia cases of patients not receiving the probiotic were identified as other lactobacilli. Among non-ICU patients ten out of 93,000 who did not receive a probiotic had bacteremia caused by lactobacilli and the isolates from four of them were identified as L. rhamnosus, thus indicating that lactobacilli can cause bacteremia also in absence of probiotic supplementation, but at a much lower frequency. The four $L$. rhamnosus isolates from the non-ICU patients showed higher similarity of the genome sequence with other L. rhamnosus strains than with L. rhamnosus GG.

Nwanyanwu et al. [61] reported 10 cases of bacteremia by lactobacilli in patients with no declared use of lactobacilli probiotics. These patients required long hospitalization $(38.5 \pm 27.6$ days). The suspected sources of infection were the gastrointestinal tract in five cases, infective endocarditis in one case and the genitourinary tract in another case. The source of infection in three cases could not be determined. Four patients had a co-infection with Candida spp. and four with enteric bacteria. Four patients died.

In a study that exploited metagenomic analysis by DNA shotgun sequencing on excised valve tissue to identify the infectious agents responsible for blood culture-negative endocarditis (BCNE), the species Limosilactobacillus fermentum was detected in one among eleven valves from 10 patients and was considered the causative agent, according to the criteria established in the study [63].

Since oral hygiene can have an impact on the occurrence of lactobacilli infections, in this survey we also considered studies on this aspect. In a study aimed at analyzing the distribution of beta-lactamase resistance genes in patients with periodontitis, it was found 
that lactobacilli, identified by $16 S$ rRNA gene sequencing, were involved in $26.3 \%$ of 129 cases of periodontitis. Limosilactobacillus fermentum was most often isolated, followed by Ligilactobacillus salivarius, L. paracasei and L. rhamnosus [64].

Finally, in a study that aimed to define the virulence of enterococci isolated from carious dentine, Ceccon Chianca et al. [65] found that all the isolates initially identified as Enterococcus faecalis by PCR were correctly identified as Lactobacillus spp. by MALDI-TOF. These isolates produced biofilm in the presence of saliva, were acidogenic, a trait involved in enamel demineralization, and could be therefore involved in caries formation.

\section{Virulence characters and proposed pathogenesis.}

Information on the physiological traits that can influence virulence in lactobacilli derived from some of the case reports surveyed in this article. Chiang et al. 2020 [45], who analyzed five isolates from a preterm girl with bacteremia and the administered probiotic, found that L. rhamnosus GG (ATCC 53103) and the administered probiotic strain, as well as isolates from blood and catheter tip, formed biofilms in all the growth conditions tested. Only a stool isolate did not form biofilm. Moreover, they observed that glucose enhanced biofilm formation. Thus, an infection dynamic was hypothesized that implies the possible bacterial translocation of L. rhamnosus GG across the immature gut epithelium of the preterm infant and enhancement of biofilm formation for the presence parenteral administration of glucose through the peripherally inserted central catheter (PICC). Four isolates from the patient (two from blood, one from the catheter tip and one from stool) and one isolate from the probiotic preparation shared five identical single nucleotide variations (SNVs) from the L. rhamnosus GG (ATCC 53103) genome available in the NCBI database. The isolate from the probiotic product exhibited an additional SNV. This finding demonstrated that short-term evolution of a probiotic can occur. One SNV common to the isolates was a nonsynonimous mutation T924G in the gene encoding a CamS family sex pheromone protein, with aminoacid substitution H308Q. A different amino acid substitution in the same protein, H294Q, was reported by Yelin et al. [62] both in blood isolates and in isolates from the probiotic that was administered to the patients. Investigations on the functional role of this protein could help elucidate if it influences biofilm formation.

Yelin et al. [62] reported five additional mutations in isolates from blood, supporting rapid in vivo evolution of the probiotic. One of these mutations, implying the amino acid substitution $\mathrm{H} 487 \mathrm{D}$ in the $r p o \mathrm{~B}$ gene encoding RNA polymerase, conferred rifampin resistance and occurred in a patient who had received for three months rifaximin together with L. rhamnosus GG.

The role of the biofilm formation capacity in virulence was confirmed by Tang et al. [36]. They observed that L. paracasei LP10266, isolated from blood and marrow samples of a patient with endocarditis, did not induce platelet aggregation and induced complement activation. However, this strain displayed a strong biofilm formation ability and adherence to human vascular endothelial cells. This strain has two spaCBA pilus gene clusters and a novel exopolysaccharides (EPS) cluster. Relating to biofilm formation capacity, it was demonstrated that in L. rhamnosus GG the SpaCBA pilus has a key role in it [66], but its coding region can be lost, i.e. during yogurt production in a minority of derivatives [67].

Zafar et al. [68] investigated the possible involvement of membrane trasporters in virulence of lactobacilli comparing six species supposed to have only a probiotic action $(L$. brevis, L. delbrueckii subsp. bulgaricus, L. crispatus, L. gasseri, L. reuteri and L. ruminis) and four species involved in infection cases (L. acidophilus, L. paracasei, L. plantarum and L. rhamnosus). They found that the latter species have a higher number of sugar, amino 
acid, peptide transporters and drug exporters. Although also the species with so far unrecognized pathogenic potential contain pore-forming toxins and drug exporters similar to those of the both probiotic and pathogenic species. However, L. paracasei, L. plantarum and L. rhamnosus have a much higher number of drug exporters, amino acid transporters, sugar transporters and unknown transporters.

Regarding patient susceptibility to lactobacilli infections, possible explanations were given by some of the case report authors. One is that diabetes mellitus, one of the main predisposing conditions, is associated with increased vascular permeability and nonocclusive microangiopathy consequent to the glycosylation of basement membranes. In addition, metabolic alterations in diabetes contribute to endothelial cell damage that could be a possible route of bacterial translocation to blood and from blood to other body sites [21]. Therefore, the combination of increasing probiotic use [7] and the increasing trend of diabetes incidence [69] could explain the rise of lactobacilli infections. In six cases reviewed here $[21,23,25,33,57,59]$ it was stated that diabetes mellitus was poorly controlled by the patient, thus indicating that a better management of this condition could reduce the probability of lactobacilli infections.

Chukwurah et al. [29] hypothesized that chronic use of ibuprofen could result in erosion of the lining of the GI tract, increasing the likelihood of the entry of lactobacilli originating from dental caries into the blood stream. Bacterial translocation from gut was deemed as possible also in other case reports [22,34,57].

According to Yelin et al. [62] the ICU pediatric patients who received L. rhamnosus GG most probably developed infection after contamination of the CVC, either directly with the probiotic strain or with stool containing the probiotic strain. However, translocation of the probiotic across the bowel wall was not excluded. No risk factors that could explain the onset of bacteremia only in some of the subjects could be identified.

\section{Discussion}

Insidious onset, severe symptomatology, long hospitalization, were common characteristics of lactobacilli infections reviewed here. The mortality rate of $8.3 \%$ was similar to that reported by Campagne et al. [27] for endocarditis, that was as high as $10 \%$ until 2018. They also found that cases of endocarditis caused by lactobacilli clearly showed an increase of reports per year since 1992. Increased annual incidence was particularly high since 2016, with fourteen cases in years 2016 - 2018 against 38 cases published in the previous 23 years, almost triplicating the number of reported cases per year. The present survey shows that the number of endocarditis reports per year further increased after 2018, reaching 23 case reports in three years with a peak of ten in 2020. Explanations can be the increased consumption of probiotics [7] and a higher percentage of the population with predisposing conditions. A question to answer is if these bacteria can still be considered to cause "rare" infections, innocuous for the general population, and which is the definition of "general population" [6]. Indeed, risk factors such as prosthetic heart valve implantation, immunosuppression for cancer or organ transplantation, as well as underlying conditions such as diabetes mellitus, regard a large percentage of individuals today.

The retrospective studies of Arbarillo et al., Nwanyanwu et al. and Yelin et al. [60,61,62] suggested that the true prevalence of infections caused by lactobacilli is higher than estimated only on the basis of case reports. In addition, in many of the reports analyzed here it was stated that lactobacilli are often disregarded as infective agents since they are considered culture contaminants [29,40,61]. 
Another obstacle for the correct estimate of lactobacilli infection prevalence is the missing reference to identification methods in some reports that were mainly focused on symptom description and treatment for which partial routinary identification and antibiotic sensitivity testing was considered sufficient. As a result, many of the reports stopped identification at the "Lactobacillus spp." level. Consequently, it is not possible to attribute with certainty those cases to lactobacilli also because a strictly related bacterium, Eggerthia catenaformis, considered to belong to the old genus Lactobacillus until 2011 , is capable to cause infections $[70,71,72,73]$ and can be confused with lactobacilli at the phenotypic level [74]. The studies that reported identification to the species level without reference to the identification method (Table 1) probably used standardized colorimetric tests or MALDI-TOF mass spectrometry, largely applied in clinical laboratories [75].

To date lactobacilli involved in infections have been little characterized at genome level but from the studies reviewed here it emerged that the ability to behave as a pathogen is inherent to the strain or clone, besides depending on patient's underlying conditions and risk factors. Studies on isolate characterization indicated the capacity to form biofilm as the most relevant virulence factor [36,62]. Strikingly, this trait varied between clones of the same probiotic L. rhamnosus GG, indicating that the genetic stability of probiotic strains must be checked to avoid use of variants with newly acquired hazardous traits. Though it was demonstrated that mutations can arise in vivo, an higher number of mutations were already present in the probiotic administered to patients $[45,62]$. Therefore, genome re-sequencing should be applied frequently to probiotic strains at the stage of production to exclude the distribution of genetic variants with increased virulence. This goes further than the current requirements of regulatory bodies that demand genome sequencing for in silico analysis of inherent risk characters of probiotics before further evaluations for use in food, food supplements [76] or LBPs [77]. Regular analysis of genetic stability to exclude genetic mutations or rearrangements that could influence virulence could allow use of safe variants of the probiotics and could be more beneficial that just avoiding use of probiotics in vulnerable patients.

Given the apparent increase of lactobacilli infection frequency shown in this survey, it would be beneficial to establish an active vigilance to identify cases attributable to these bacteria in healthcare settings, isolate strains and characterizing them for the presence of virulence traits. This could lead to a better selection of probiotic lactobacilli or their variants that can be safely administered also to vulnerable subjects.

Particular attention should be payed to traditional fermented products as possible sources of lactobacilli able to cause infections. The development of autochthonous cultures with well defined characteristics and their use to prevent the predominance of adventitious strains with unknown characteristics would improve safety of these foods.

Supplementary Materials: The following supporting information can be downloaded at: www.mdpi.com/xxx/s1, Table S1.

Author Contributions: All authors equally contributed to conceptualization, methodology, writing and editing. All authors have read and agreed to the published version of the manuscript.

Funding: This research received no external funding.

Institutional Review Board Statement: Not applicable.

Informed Consent Statement: Not applicable.

Data Availability Statement: Not applicable.

Conflicts of Interest: The authors declare no conflict of interest. 
1. Oren, A.; Garrity. G.M. Notification that new names of prokaryotes, new combinations, and new taxonomic opinions have appeared in volume 70, Part 4 of the IJSEM. Int. J. Syst. Evol. Microbiol. 2020, 70, 4050@4060.

2. Mota de Carvalho, N.; Costa, E.M.; Silva, S.; Pimentel, L.; Fernandes, T.H.; Estevez Pintado, M. Fermented Foods and Beverages in Human Diet and Their Influence on Gut Microbiota and Health. Fermentation 2018, 4, 90.

3. FAO/WHO. Evaluation of Health and Nutritional Properties of Probiotics in Food Including Powder Milk with Live Acid Bacteria. Report of a Joint FAO/WHO Expert Consultation, 2001, Córdoba, Argentina. (accessed 8 February 2022).

4. Marco, M.L.; Sanders, M.E.; Gänzle, M.; Arrieta, M.C.; Cotter, P.D.; De Vuyst, L.; Hill, C.; Holzapfel, W.; Lebeer, S.; Merenstein, D.; Reid, G.; Wolfe, B.E.; Hutkins, R. The International Scientific Association for Probiotics and Prebiotics (ISAPP) consensus statement on fermented foods. Nat Rev Gastroenterol Hepatol. 2021, 18, 196@208. doi: 10.1038/s41575-020-00390-5.

5. Food and Drug Administration (FDA). Federal Register Notice - the GRAS Final Rule. 81 FR 54960 - August 17, 2016. https://www.federalregister.gov/documents/2016/08/17/2016-19164/substances-generally-recognized-as-safe. (accessed 8 February 2022).

6. EFSA Panel on Biological Hazards (BIOHAZ). Update of the list of QPS-recommended biological agents intentionally added to food or feed as notified to EFSA 13: suitability of taxonomic units notified to EFSA until September 2020. EFSA Journal, 2021, 19, e06377.

7. European Probiotic Association (IPA). European Probiotic Market Insights - 2019. https://www.ipaeurope.org/wp-content/uploads/2020/07/2019-Probiotic-Market-Insight.pdf. (accessed 8 february 2022).

8. Pot, B.; Vandenplas, Y. Factors that influence clinical efficacy of live biotherapeutic products. Eur. J. Med. Res. 2021, 26, Article number: 40 .

9. De Simone, C. The Unregulated Probiotic Market. Clin. Gastroenterol. Hepatol. 2019, 17, $809 \odot 817$.

10. Rossi, F.; Amadoro, C.; Colavita, G. Members of the Lactobacillus Genus Complex (LGC) as Opportunistic Pathogens: A Review. Microorganisms 2019, 7, 126.

11. Morgan, R.L.; Preidis, G.A.; Kashyap, P.C. ; Weizman, A.V.; Sadeghirad, B.; McMaster Probiotic, Prebiotic, and Synbiotic Work Group. Probiotics Reduce Mortality and Morbidity in Preterm, Low-Birth-Weight Infants: A Systematic Review and Network Meta-analysis of Randomized Trials. Gastroenterology 2020, 159, 467®480.

12. Tao, Y.W.; Gu, Y.L.; Mao, X.Q.; Zhang, L.; Pei, Y.F. Effects of probiotics on type II diabetes mellitus: a meta-analysis. J. Transl. Med. 2020, 18, Article number: 30.

13. Zhang, X.L.; Chen, M.H.; Geng, S.T.; Yu, J.; Kuang, Y.Q.; Luo, H.Y.; Wan, K.H. Effects of Probiotics on Diarrhea and CD4 Cell Count in People Living With HIV: A Systematic Review and Meta-Analysis. Front. Pharmacol. 2021, 12:570520.

14. Madamanchi, C.; Hota, P.; Jhala, K.; Robertson, M.; Di Carli, M.; Aghayev, A. Multimodality Imaging in Prosthetic Valve Endocarditis With Septic Coronary Embolism. Circulation: Cardiovascular Imaging 2019, 12:e009298.

15. Osman, A.; Taipale, M.; Najjar, M.; Osman, B. Lactobacillus paracasei endocarditis of bioprosthetic aortic valve presenting with recurrent embolic strokes. Access Microbiol. 2019, 1:e000038.

16. Ajam, M.; Adam, O.; Yeddi, A.; Kahlid, M.; Shokr, M.; Afonso, L. Prosthetic Aortic Valve Endocarditis in a Patient With BirtHogg-Dube Syndrome due to Lactobacillus paracasei. Cardiol. Res. 2019, 10, 245-248.

17. Gueorguieva, I.; Kosti, J.; Makandura, M.; Ismail, R. A Rare Presentation of Lactobacillus Paracasei Endocarditis With Involvement of Aortic Prosthetic Valve in a Patient With Septic Shock Due to Acute Cholecystitis. The Amer. J. Gastroenterol. 2019, 114, p S743.

18. Sharma, N.; Ravi, D.; Saqib, N.; Pir, M.S.; Dougherty, C.; Porter, E. A curious case of prosthetic valve endocarditis due to lactobacillus. Chest J. Monday abstract posters, 2019, 156, 4, Supplement, A308-A309, October 01,. DOI:

19. Moosavi, M.; Zuckerman, J.E. Lactobacillus Endocarditis-Associated Glomerulonephritis Complicated by anti-Coagulant Nephropathy and Renal Amyloidosis", Case Rep. Pathol. 2019, Article ID 6198380.

20. Celis Castañeda, L.A.; Morales Camacho, W.J.; Durán Ochoa, N.M. Sepsis due to Lactobacillus reuteri in an extreme preterm newborn: case report. Arch. Argent. Pediatr. 2019, 117, e509-e513.

21. Omar, A.M.; Ahmadi, N.; Ombada, M.; Fuscaldo, J.; Siddiqui, N,; Safo, M.; Nalamalapu, S. Breaking Bad: a case of Lactobacillus bacteremia and liver abscess, J. Commun. Hosp. Int. Med. Perspect. 2019, 9:3, 235-239.

22. Eldin, M.S.; Liaqat, S.; Awad K.; Aldergash, S. Lactobacillus Bacteremia in a Critically Ill Patient. American Journal of Medical Case Reports 2019, 7, 191-192.

23. Latifi, A.N.; Saeyeldin, A.; Simms, M. Lactobacillus acidophilus bacteremia in a diabetic patient. J. Case Rep. Images Infect. Dis. 2019, 2, 100005Z16AL2019.

24. Cavicchiolo, M.E.; Magnani, M.; Calgaro, S.; Bonadies, L.; Castagliulo, I.; Morelli, L.; Verlato, G.; Baraldi, E. Neonatal sepsis associated with Lactobacillus supplementation. J. Perinat. Med. 2019, 48, 87-88.

25. Ozer, M.; Goksu, S.Y.; Shahverdiani, A.; Mustafa, M. Lactobacillus acidophilus-Induced Endocarditis and Associated Splenic Abscess. Case Rep Infect Dis. 2020, 2020,1382709.

26. Tavernese, A.; Stelitano, M.; Mauceri, A.; Mollace, R.; Uccello, G.; Romeo, F.; Cammalleri, V. Progression of Lactobacillus plantarum prosthetic valve endocarditis followed by transesophageal echocardiogram. Int. J. Infect. Dis. 2020, 97, 160-161.

27. Campagne, J.; Guichard, J.F.; Moulhade, M.C.; Kawski, H.; Maurier, F. Lactobacillus endocarditis: a case report in France and literature review. IDCases 2020, 21, e00811.

28. Pasala, S.; Singer, L.; Arshad, T.; Roach, K. Lactobacillus endocarditis in a healthy patient with probiotic use. IDCases 2020, 22, e00915. 
29. Chukwurah, V.O.; Takang, C.; Uche, C.; Thomas, D.B.; El Masry, W.; Toka, H.R. Lactobacillus acidophilus Endocarditis Complicated by Pauci-Immune Necrotizing Glomerulonephritis. Case Rep. Med. 2020, 2020, 1607141.

30. Campbell, R.E.; Miller, A.; Afroze, A. Native valve endocarditis secondary to Lactobacillus paracasei bacteremia. Consultant 2020, 60, 27@28.

31. Minto, T.; Bullock, N.; Deglurkar, I.; Hughes, O. Asymptomatic bilateral obstructing ureteric calculi resulting in lactobacillaemia and endocarditis requiring emergency aortic valve replacement. Urol. Case Rep. 2020, 32, 101218.

32. Bergagnini, I.; Hmoud, H.; Nocerino, A.; Ivanina, E. Gut Friend or Foe: A Case of Lactobacillus Rhamnosus Endocarditis from Probiotic Use. Am. J. Gastroenterol. 2020, 115, S933.

33. Antoun, M.; Hattab, Y.; Akhrass, F.A.; Hamilton, L.D. Uncommon Pathogen, Lactobacillus, Causing Infective Endocarditis: Case Report and Review. Case Rep. Infect. Dis. 2020, 2020, 8833948.

34. Agrawal, S.; Tuchman, E.S.; Bruce, M.J.; Theodorou, M.E. Fatal Lactobacillus endocarditis in a patient with transcatheter aortic valve replacement. BMJ Case Rep. 2020, 13, e236835.

35. Sendil, S.; Shrimanker, I.; Mansoora, Q.; Goldman, J.; Nookala, V.K Lactobacillus rhamnosus Bacteremia in an Immunocompromised Renal Transplant Patient. Cureus 2020, 12, e6887. doi: 10.7759/cureus.6887

36. Tang, Q.; Hao, Y.; Wang, L.; Lu, C.; Li, M.; Si, Z.; Wu, X.; Lu. Z.; Characterization of a bacterial strain Lactobacillus paracasei LP10266 recovered from an endocarditis patient in Shandong, China. BMC Microbiol. 2021, 21, 183.

37. Bergas, A.; Rivera, S.; Torrecillas, M.; Cuervo, G. Native and prosthetic transcatheter aortic valve infective endocarditis due to Lactobacillus rhamnosus. Enferm. Infecc. Microbiol. Clin. (Engl. Ed.) 2021, Jul 2, S0213-005X(21)00196-8.

38. M.H.; Khalil. Lactobacillus endocarditis, a sinister consequence of an innocuous bacterium. Chest J. Cardiovascular Dis. 2021, 160, 4, Supplement, A240.

39. Argotsinger, J.;, Beganovic, M.; Taha, R.; Anderson, M. Lactobacillus Endocarditis Complicated by Presumed Vertebral Osteomyelitis and Embolic Stroke. Infect. Dis. Clin. Pract. 2021, 29, e418-e419.

40. Grazioli-Gauthier, L.; Rigamonti, E.; Leo, L.A.; Martinetti Lucchini, G.; Lo Priore, E.; Bernasconi, E. Lactobacillus jensenii mitral valve endocarditis: Case report, literature review and new perspectives. IDCases 2022, 27, e01401.

41. Lim, E.T.A.; Hamdulaya, K.A.; Heath, A.J.; Bridgman, P.G.; Dalton, S.C.; Lyons, O.T.; Laws, P.E. Peroneal mycotic pseudoaneurysm: The lactobacillus strikes back. Annals of Vascular Surgery - Brief Reports and Innovations 2022, 2, 100031.

42. Haziri, D.; Prechter, F.; Stallmach, A. Yoghurt-induced Lactobacillus bacteremia in a patient with Crohn's disease on therapy with ustekinumab and concomitant HIV-Infection. Z. Gastroenterol. 2021, 59, 317@320.

43. Matsuura, H.; Kiura, Y.; Ito, T.; Fujita, R.; Kajitani, S.; Kageyama, H.; Suganami, Y.; Kishida, M. Lactobacillus bacteremia: a diagnostic clue of rectal cancer. QJM 2021, 114, 122@123.

44. Aydoğan, S.; Dilli, D.; Özyazici, A.; Aydin, N.; Şimşek, H.; Orun, U.A.; Aksoy, Ö.N. Lactobacillus rhamnosus Sepsis Associated with Probiotic Therapy in a Term Infant with Congenital Heart Disease. Fetal Pediatr. Pathol. 2021, 20, $1 \odot 5$.

45. Chiang, M.C.; Chen, C.L.; Feng, Y.; Chen, C.C.; Lien, R.; Chiu, C.H. 2020. Lactobacillus rhamnosus sepsis associated with probiotic therapy in an extremely preterm infant: pathogenesis and a review for clinicians. J. Microbiol. Immunol. Infect. 2021, 54, 575@580.

46. Biesiada, G.; Jacek Czepiel, R.K.; Stażyk, K.; Kędzierska, J.; Garlicki, A. Meningoencephalitis caused by Lactobacillus plantarum - case report. Int. J. Neurosci. 2019, 129, 715๑718.

47. Koyama, S.; Fujita, H.; Shimosato, T.; Kamijo, A.; Ishiyama, Y.; Yamamoto, E.; Ishii, Y.; Hattori, Y.; Hagihara, M.; Yamazaki, E.; Tomita, N.; Nakajima, H. On behalf of the Yokohama Cooperative Study Group for Hematology (YACHT). Septicemia from Lactobacillus rhamnosus GG, from a Probiotic Enriched Yogurt, in a Patient with Autologous Stem Cell Transplantation. Probiotics Antimicrob. Proteins 2019, 11, 295॰298.

48. Maillet, F.; Passeron, A.; Podglajen, I.; Ranque, B.; Pouchot, J. Lactobacillus delbrueckii urinary tract infection in a male patient. Infection urinaire masculine à Lactobacillus delbrueckii. Med. Mal. Infect. 2019, 49, 226॰228. doi: 10.1016/j.medmal.2018.11.006.

49. De Freitas, G.; Toor, A.; Bekele, Y.; Patel, N.; Kannangara, S. Perinephric Abscess and Bacteremia Due to Lactobacillus Species in a Diabetic Adult An Uncommon Presentation. Infect. Dis. Clin. Pract. 2019, 27, 366@369.

50. Tanaka, Y.; Soda, H.; Fukuda, Y.; Nio, K.; Ono, S.; Tomono, H.; Shimada, M.; Yoshida, M.; Harada, T.; Umemura, A.; Iwasaki, K. Vildagliptin-induced ground-glass nodules mimicking lung metastases in a cancer patient receiving Lactobacillus probiotic supplementation. Thorac. Cancer 2020, 11, 470@474.

51. Lilitwat, W.; Reeve, S.; Womack, C.; Kasemsri, T. Pediatrics, Texas Tech University Health Science Center, Lubbock, TX. A Rare Bacteria: Lactobacillus Rhamnosus in Pediatric Lung Abscess. Lung infection, Immunodeficiency / Thematic Poster Session. Am. J. Respir. Crit. Care Med. 2020, 201, A7171. doi.org/10.1164/ajrccm-conference.2020.201.1_MeetingAbstracts.A7171.

52. Mohan, A.; Rubin, J.; Chauhan, P.; Ramirez, J.L. Giese, G. Renal and perinephric abscesses involving Lactobacillus jensenii and Prevotella bivia in a young woman following ureteral stent procedure. J Community Hosp Intern Med Perspect. 2020, 10, $162 \odot 165$.

53. Tan, C.; Howard, J.L.; Bondy, L. Prosthetic joint infection after total hip arthroplasty caused by Lactobacillus paracasei. CMAJ 2020, 192, E1357-E1360.

54. Vyas, V.; Mian, S.; Paolino, K.; Siddique, Z. Lactobacillus masticator abscess after probiotics consumption. Proc. (Bayl. Univ. Med. Cent.) 2021, 34, 93-94.

55. Ranchal, P.; Gupta, R.; Goldberg, R.; Lobo, S.A.; Pascual, A.; El Khoury, M.Y. Penicillin-Sensitive Lactobacillus jensenii Bacteremia. Am J Ther. 2021, 28, e250-e252. doi: 10.1097/MJT.0000000000001061.

56. Ramos-Coria, D.; Canto-Losa, J.; Carrillo-Vázquez, D.; Carbajal-Morelos, L.; Estrada-León, R.; Corona-Rodarte, E. Lactobacillus gasseri liver abscess and bacteremia: a case report. BMC Infect. Dis. 2021, 21, 518. https://doi.org/10.1186/s12879-021-06181-w.5. 
57. Miwa, T.; Tanaka, H.; Shiojiri, T. Infected pancreatic necrosis and retroperitoneal abscess associated with Lactobacillus paracasei. BMJ Case Rep. 2021, 14, e243936.

58. Toyoshima, H.; Shibahara, T.; Tanigawa, M.; Masuda, N.; Ishiguro, C.; Tanaka, H.; Nakanishi, Y.; Sakabe, S. Lactobacillus paragasseri as a novel causative pathogen of cavernosal abscess. IDCases 2021, 26, e01320.

59. Hubbard, J.; Jariwala, B.; Hill, A.; Gega, A.; Palesty, J.A. A new bacterium, Lactobacillus acidophilus, Causing Necrotizing Fasciitis. Am. Surg. 2018, 84, e61-3.

60. Albarillo, F.S.; Shah, U.; Joyce, C.; Slade, D. Lactobacillus rhamnosus Infection: A Single-center 4-year Descriptive Analysis. J. Glob. Infect. Dis. 2020, 12, 119-123.

61. Nwanyanwu, C.; Shobayo, A.; Ghitan, M.; Chapnick, E.; Kuhn-Basti, M.; Lin, Y.S.; Simon, S.; Li, R. Lactobacillus: Friend or Foe. Open Forum Infect. Dis. 2020, 7, S147.

62. Yelin, I.; Flett, K.B.; Merakou, C.; Mehrotra, P.; Stam, J.; Snesrud, E.; Hinkle, M.; Lesho, E.; McGann, P.; McAdam, A.J.; Sandora, T.J.; Kishony, R.; Priebe, G.P. Genomic and epidemiological evidence of bacterial transmission from probiotic capsule to blood in ICU patients. Nat. Med. 2019, 25, 1728-1732.

63. Million, M.; Gaudin, M.; Melenotte, C.; Chasson, L.; Edouard, S.; Verdonk, C.; Prudent, E.; Amphoux, B.; Meresse, S.; Dorent, R.; Lepidi, H.; La Scola, B.; Gorvel, J.P.; Desnues, C.; Raoult, D. Metagenomic Analysis of Microdissected Valvular Tissue for Etiological Diagnosis of Blood Culture-Negative Endocarditis. Clin. Infect. Dis. 2020, 70, 2405-2412.

64. Kalali, N.; Kadkhoda, Z.; Amid, R.; Ghourchian, S.; Douraghi, M. Identification of oral anaerobic bacteria and the beta-lactamase resistance genes from Iranian patients with periodontitis. Anaerobe 2022, 10, 102515.

65. Ceccon Chianca, G.; Azeredo Alves Antunes, L.; Oliveira Ornellas, P.; Piedade Gonçalves Neves, F.; Cardoso Corrêa Póvoa, H.; Lopes Pontes Póvoa Iorio, N. Virulence of Lactobacillus spp. misidentified as Enterococcus faecalis from children's carious dentine. Acta. Odontol. Scand. 2022, 80, 21-28.

66. Lebeer, S.; Claes, I.; Tytgat, H.L.P.; Verhoeven, T.L.A.; Marien, E.; von Ossowski, I.; Reunanen, J.; Palva, A.; de Vos, W.M.; De Keersmaecker, S.C.J.; Vanderleyden, J. Functional analysis of Lactobacillus rhamnosus GG pili in relation to adhesion and immunomodulatory interactions with intestinal epithelial cells. Appl. Environ. Microbiol. 2012, 78, 185-193.

67. Stage Strickertsson, M.; Hui, Y.; Nielsen, D.S.; Vera-Jiménez, N.I.; Olsen, J.; Sandelin, A.; Wichmann, A. Genomic Stability and Phenotypic Characteristics of Industrially Produced Lacticaseibacillus rhamnosus GG in a Yogurt Matrix. Appl. Environ. Microbiol. 2021, 87, e0157521.

68. Zafar, H.; Saier, M.HJr. Genomics of the Transport Proteins of Ten Lactobacillus Strains. Genes 2020, 11, 1234.

69. Lin, X.; Xu, Y.; Pan, X.; Xu, J.; Ding, Y.; Sun, X.; Song, X.; Ren, Y.; Shan, P.F. Global, regional, and national burden and trend of diabetes in 195 countries and territories: an analysis from 1990 to 2025. Sci. Rep. 2020, 10, 14790.

70. Foronda, C.; Calatrava, E.; Casanovas, I.; Martín-Hita, L.; Navarro-Marí, J.M.; Cobo, F. Eggerthia catenaformis bacteremia in a patient with an odontogenic abscess. Anaerobe 2019, 57, 115-116.

71. Wang, M.; Zhang, M.; Xu, H. First report of bacteremia caused by Eggerthia catenaformis in a patient with gastric malignancy in China. Anaerobe 2020, 64, 102218.

72. Sakkas, A.; Nolte, I.; Heil, S.; Mayer, B.; Kargus, S.; Mischkowski, R.A.; Thiele, O.C. Eggerthia catenaformis infection originating from a dental abscess causes severe intestinal complications and osteomyelitis of the jaw. GMS Interdiscip. Plast. Reconstr. Surg. DGPW 2021, 10, Doc02.

73. Sreckovic, S.; Kadija, M.; Ladjevic, N.; Starcevic, B.; Stijak, L.; Milovanovic, D. The first case of septic arthritis of the knee caused by Eggerthia catenaformis. Anaerobe 2022, 73, 102503.

74. Salvetti, E.; Felis, G.E.; Dellaglio, F.; Castioni, A.; Torriani, S.; Lawson, P.A. Reclassification of Lactobacillus catenaformis (Eggerth 1935) Moore and Holdeman 1970 and Lactobacillus vitulinus Sharpe et al. 1973 as Eggerthia catenaformis gen. nov., comb. nov. and Kandleria vitulina gen. nov., comb. nov., respectively. Int. J. Syst. Evol. Microbiol. 2011, 61, 2520-2524.

75. Torres-Sangiao, E.; Leal Rodriguez, C.; García-Riestra, C. 2021. Application and Perspectives of MALDI-TOF Mass Spectrometry in Clinical Microbiology Laboratories. Microorganisms 2021, 9, 1539.

76. European Food Safety Authority. EFSA statement on the requirements for whole genome sequence analysis of microorganisms intentionally used in the food chain. EFSA J. 2021, 19, 6506.

77. Dreher-Lesnick, S.M.; Stibitz, S.; Carlson, P.E.Jr. US regulatory considerations for development of live biotherapeutic products as drugs. Microbiol. Spectrum. 2017, 5, 1-6. 